\title{
A dialética do localismo
}

e do cosmopolitismo nas

narrativas gráficas de

Marjane Satrapi

\section{Marcio Serelle}

Professor do Programa de PósGraduação em Comunicação Social da PUC Minas e pesquisador do CNPq. Email: marcio.serelle@cnpq.pq.br

\footnotetext{
${ }^{1}$ A obra Persépolis foi lançada originalmente na França, em quatro volumes, entre 2000 e 2003; Bordados, em 2003; e Frango com ameixas, em 2004.
}

Resumo: Os romances gráficos de Marjane Satrapi, assim como suas adaptações cinematográficas, narram histórias iranianas por meio de formas pop de expressão. A partir da apropriação da noção de dialética do localismo e do cosmopolitismo em Candido (2000), este artigo propõe, por meio da análise dessas obras (Persépolis, Bordados e Frango com ameixa), desdobrar essa integração para além das relações entre forma e fundo, colocando em relevo outras camadas de diálogo entre contextos que questionam representações estereotipadas do Irã e da mulher iraniana. Em seu cerne, o artigo recupera o debate acerca de modos de narrar eventos traumáticos, tendo em vista uma geração recente que busca formas não canônicas de testemunho de situações-limite, que passam usualmente pelo uso da imagem e por gêneros de entretenimento.

Palavras-chave: Testemunho, graphic novel, estereótipo, Irã, Marjane Satrapi

Title: The dialectics of localism and cosmopolitism in Marjane Satrapi's graphic narratives

\begin{abstract}
Marjane Satrapi's graphic novels as well their film adaptations show Iranians stories through pop forms of expression. Considering the dialectics of localism and cosmopolitism in Candido (2000), this article proposes to examine Satrapi's work (Persepolis, Embroideries, and Chicken with plums) and extend the dialectical notion beyond the relations between form and content. It aims at revealing that this dialectics is present in other ways of negotiation between contexts, which questions stereotyped representations of Iran and Iranian women. This article also retrieves the debate about forms of narrating traumatic events, in view of a recent generation that seeks non canonical forms of testimony concerning extreme situations. These forms usually involve the use of images and entertainment genres.
\end{abstract}

Keywords: Testimony, graphic novel, stereotype, Iran, Marjane Satrapi.

\section{Introdução}

As narrativas gráficas da iraniana Marjane Satrapi (Persépolis, Bordados e Frango com ameixas $)^{1}$, escavam, na cultura midiática, uma outra visibilidade para a sociedade da autora, notadamente para a representação da mulher naquele país, usualmente marcada, no Ocidente, por uma série de estereótipos. A motivação para produzir Persépolis, segundo Satrapi (2013), veio do desacordo dela em relação às imagens do Irã veiculadas na mídia dominante do Ocidente, circunscritas quase sempre, de acordo com a quadrinista, ao fundamentalismo e ao terrorismo, multiplicando aiatolás, véus e sequestradores. Radicada na França desde 1994, escreveu, em depoimento sobre a fatura da obra, que as cenas do 
${ }^{2}$ No original: "I've been justifying why it isn't negative to be Iranian for almost twenty years."

${ }^{3}$ No original: "[...] succeeds in juxtaposing both word and image in such a way that she effectively revises no only the aesthetic of the comic strip or animated cinematic media but also negotiates a new understanding of affective memory and storytelling".
Irã que ela e seus amigos viam na televisão não representavam sua experiência: "Tenho justificado, por quase vinte anos, porque não é negativo ser uma iraniana" (SATRAPI, 2013: 10, tradução nossa)².

Consciente de que nosso conhecimento sobre o mundo é necessariamente mediado por imagens, Satrapi, informada por Maus, a narrativa de Art Spiegelman sobre a Shoah, encontrou nos quadrinhos sua forma de expressão. Embora seja, por vezes, considerada uma forma menor de literatura, a graphic novel permite a ela o ingresso num cosmopolitismo, em que a língua geral do entretenimento, de grande força comunicacional, serve a suas histórias iranianas. Entre elas, muitas com forte traço testemunhal acerca de situações-limite, que, há algum tempo, seriam tabus para narrativas gráficas como a arte sequencial e a animação (a obra Persépolis foi adaptada para o cinema pela própria Satrapi e Vincent Paronnaud, em 2007; e Frango com ameixas tornou-se filme com atores e animação, dirigido também pela dupla, em 2011). Como assinala Weber-Fève (2011: 324, tradução nossa), a autora "é bem-sucedida em justapor palavra e imagem de um modo em que efetivamente revisa não somente a estética da tira de quadrinhos ou do cinema de animação como também negocia um novo entendimento de memória afetiva e narração”3.

No limiar entre o entretenimento ocidental - os quadrinhos e a animação - e a matéria da vida levada no Irã, Satrapi perfaz, em camada mais visível, a dialética do cosmopolitismo e do localismo. Para Amy Malek (2006), esse ponto de passagem nas obras permite a hibridação entre gêneros do Ocidente e aspectos da história e da cultura iraniana, gerando um campo dialético, de onde se questionam tanto as representações hegemônicas do Irã e dos iranianos como se traduz a inadequação do exílio.

Deslocamos, para este artigo, a expressão dialética do localismo e do cosmopolitismo do pensamento de Antonio Candido, que, em ensaio de Literatura e sociedade, acerca da vida cultural brasileira, aponta momentos de integração entre duas tendências, descritas em seus extremos e que, por vezes, só existem de forma programática: uma localista, em que se reivindica, por vezes, de forma "violenta" um nacionalismo nas artes; uma cosmopolita, "conformada" e de franca integração a padrões e formas europeus. Para Candido, contudo, o que emergiu, até então, de mais significativo em nossa cultura literária - em termos de obra e personalidade - situou-se em um ponto ideal entre as duas tendências.

Pode-se chamar dialético a este processo porque ele tem realmente consistido numa integração progressiva de experiência literária e espiritual, por meio da tensão entre o dado local (que se apresenta como substância da expressão) e os moldes herdados da tradição européia (que se apresentam como forma de expressão). (CANDIDO, 2000: 110).

Essa noção ancora a investigação deste artigo, embora devamos marcar o caráter específico mais complexo dessa dialética em Satrapi, pois a forma cosmopolita a que nos referimos não resulta propriamente de uma tradição, no sentido da arte elevada europeizada da grande divisão moderna, mas de uma cultura global de entretenimento (o que possivelmente provocaria resistência a Antonio Candido), por vezes considerada indigna de representar eventos traumáticos. A dialética ganha, ainda, diferentes nuanças nas obras da iraniana, uma vez que implica determinada complexidade nos usos do pop e na relação que estabelece com a cultura de consumo. Ela não é, ainda, composta somente pelo "dado local" e a "expressão cosmopolita", mas por diálogos em instâncias diversas, inclusive no que se refere às formas narrativas. Por fim, convém ressaltar novamente que esse espaço entre o local e cosmopolita nasce de uma diáspora iraniana, logo, de uma produção cultural de uma artista exilada, que remete constantemente a questões de identidade. Portanto, enquanto, para o pensamento moderno de Candido, essa dialética ligase à ideia de formação do nacional por meio dessas tendências oscilantes entre os intelectuais, a integração que apontamos, não sem conflitos, em Satrapi, já é 
de outra ordem, uma vez que diz respeito às migrações e às relações diaspóricas em uma cultura mundializada, em que a adoção de certos aspectos cosmopolitas resulta em visibilidade, sem, contudo, apagar os localismos.

Interessa-nos, assim, refletir sobre dois principais aspectos dessas narrativas: (1) elas parecem consolidar um eixo que já não distingue modos mais ou menos dignos para o testemunho e a representação memorialística de situações-limites, evidenciando uma geração (de criadores e de público) que, tendo crescido na cultura midiática, utiliza-se do pop como forma legítima de expressão e transmissão de eventos traumáticos; (2) elas se inserem num cosmopolitismo, afinado ao entretenimento ocidental, que é usado, por vezes, como subversão à política cultural pós-revolucionária no Irã. No entanto, as narrativas também marcam suas diferenças na travessia entre os polos culturais a que se refere, criticando aspectos tanto das sociedades ocidentais como da iraniana, e acenando para formas sensíveis de retorno ao Oriente.

\section{O exílio no pop}

A representação de eventos traumáticos enfrenta, pelo menos desde após a Segunda Guerra, dilemas que vão do reconhecimento de uma impossibilidade à proposição de formas que seriam mais adequadas à narrativa do intolerável. No primeiro caso, sustenta-se a conviç̧ão de que a experiência de situações-limites guerras, genocídios, massacres e ditaduras, entre outras - é indizível, no sentido em que o sobrevivente é abandonado pela linguagem e deve recusar a metáfora, sob risco de estetizar sua vivência do horror. No segundo, valoriza-se o testemunho pela palavra como forma apropriada quando ele é fragmento de um mundo desmoronado e escapa a uma organização narrativa coesa. Assim, de acordo com Seligmann-Silva (2005: 85), "literalização e fragmentação são duas características centrais (e apenas à primeira vista incompatíveis) do discurso testemunhal". A primeira se refere justamente à incapacidade de se traduzir o horror em imagens; a segunda, a uma impossibilidade de narrar a memória em uma cadeia contínua, pois o testemunho é um discurso hesitante, que tenta reunir e contextualizar o fragmentário.

A virtude conferida a esse tipo de narrativa em ruínas pode ser compreendido pelo caráter sagrado da palavra na cultura. Para Rancière (2010: 137), a logofilia afirma-se, no caso do testemunho, por meio de uma tripla negatividade: "é o oposto da imagem, que é idolatria; (...) é a palavra do homem incapaz de falar; finalmente, porque é a palavra do homem obrigado à palavra por uma palavra mais poderosa que a sua". Mesmo quando do testemunho audiovisual, valorizamse, frequentemente, as obras que apontam para o silêncio, em que a sintaxe de imagens recusa-se ao espetáculo midiático, pois as formas da cultura de massa seriam indignas desses eventos. Um caso paradigmático desse consenso - mas que, segundo Huyssen (2003), começa a perder força -, é o cotejo entre os filmes A lista de Schindler, de Spielberg, e Shoah, de Lanzmann, sobre o Holocausto. Huyssen descreve assim o debate:

${ }^{4}$ No original: "Spielberg's film, playing to mass audiences, fails to remember properly because it represents, thus fostering forgetting: Hollywood as fictional substitute for 'real history' . Lanzmann's refusal to represent, on the other hand, is said to embody memory in the proper way precisely because it avoids the delusions of a presence of that which is to be remembered. Lanzmann's film is praised as something like heroic effort in Kulturkampf against the memory industry, and its refusal to re-present, its adherence to Bilderverbot, becomes the ground for its authenticity".
O filme de Spielberg, veiculado para audiências massivas, falha em recordar de maneira apropriada porque ele representa, logo provocando esquecimento: Hollywood como substituto ficcional para a "história real". A recusa de Lanzmann em representar, por outro lado, é considerada como uma forma adequada de incorporar a memória precisamente porque evita as ilusões de uma presença que é para ser recordada. O filme de Lanzmann é elogiado como uma espécie de esforço heróico na Kulturkampf contra a indústria da memória, e sua recusa a re-apresentar, sua aderência ao Bilderverbot, torna-se o fundamento para sua autenticidade. (HUYSSEN, 2003: 124-125, tradução nossa).

O Bilderverbot - literalmente, proibição de imagens - refere-se a uma iconofobia que antecede em muito as críticas à indústria cultural e ao espetáculo do século 
${ }^{5}$ Ver a esse respeito o ensaio de Arlindo Machado (2001), "O quarto iconoclasmo".

${ }^{6}$ No original: "[...] suddenly the government in our country decided we were worth half of the men - my witness counts half that of a mentally handicapped man just because he's a man."

${ }^{7}$ No original: "[...] to fuse Western genres of memoir and comics with Iranian history, culture, and her own mixed sensibilities to create a "third space" environment from which to speak and tell her hybrid tale."
$X X$, pois enraizada em preceitos religiosos e na depreciação platônica do mundo das aparências ${ }^{5}$. A questão é até que ponto essa investida contra as imagens é de fato compartilhada significativamente nas sociedades midiatizadas ou permanece confinada a uma intelligentzia apocalíptica. Convém ainda questionar de que forma essa noção de uma memória autêntica, colocada em contraponto a uma indústria da memória, constrange, de fato, uma geração de autores que, criada no cerne do pop, utiliza-se dele para o biográfico, que envolve, também, o testemunho do horror.

A discussão de Hirsch (2008) acerca dos relatos de "pós-memória" levanta alguns pontos que se aproximam de questões também atinentes às narrativas de Satrapi, embora os quadrinhos da autora iraniana não pertençam a esse conjunto de obras. A "pós-memória" reúne, segundo Hirsch, produções de uma "segunda geração" de escritores e artistas a partir de uma memória "herdada" de familiares que atravessaram eventos traumáticos massivos. Hirsch não considera a "pós-memória" uma posição identitária, mas uma "estrutura geracional de posição", em que o gráfico - a discussão dela é em torno da fotografia - é privilegiado como forma de mediação. Segundo ela, "mais do que narrativas orais e escritas, imagens que sobrevivem a uma devastação massiva e que vivem mais que seus sujeitos e donos funcionam como assombrações fantasmagóricas de um mundo passado irremediavelmente perdido" (HIRSCH, 2008: 115). Essas fotografias nos permitiriam "não somente ver e tocar o passado, mas reanimá-lo" (HIRSCH, 2008: 115). A partir da identifica ção dessa valorização das imagens, Hirsch conclui que as obras desses descendentes deixam claro que mesmo o conhecimento familiar mais íntimo é irremediavelmente mediado por imagens e narrativas amplamente disponíveis da cultura midiática. Como exemplo, a ensaísta cita uma imagem de Maus, em que Spiegelman, mesmo em trabalho rente, por meio de entrevistas, com o testemunho, imagina a experiência do pai em Auschwitz por meio da conhecida fotografia de Margaret Bourke-White tirada quando da libertação dos prisioneiros em Bunchenwald, na Alemanha.

A narrativa gráfica de Marjane Satrapi também propõe-nos essa revisão acerca do testemunho por meio das imagens. Se a cultura midiática é uma guerra de relatos e uma disputa por sentidos na mediação narrativa dos acontecimentos (fotos, reportagens, documentários, filmes de ficção - em que podemos incluir, no caso do Irã, o hollywoodiano Argo, de Ben Affleck), Satrapi insere-se nessa cultura por meio de seus quadrinhos chapados e ligeiros cuja despretensão permite, no entanto, destilar a crítica tanto a estereótipos criados no Ocidente como à guinada religiosa da revolução popular de 1979, que delegou à mulher lugar secundário. "De repente, o governo em nosso país decidiu que nós valemos metade de um homem. Meu testemunho vale metade de um homem incapacitado mentalmente só porque, ainda assim, ele é um homem" (SATRAPI, 2007: 151) ${ }^{6}$, ela exemplifica.

De família marxista, que inicialmente colocou suas fichas no levante popular, Satrapi era criança quando a revolução eclodiu no Irã. Como narrado com humor nas primeiras páginas de Persépolis, seu livro preferido aos nove anos era "O materialismo dialético" em quadrinhos, no que a narradora conclui: "Eu me divertia vendo como Deus e Marx eram parecidos. O cabelo do Marx era um pouco mais crespo" (SATRAPI, 2007a: s.p.). A obra narra de sua infância à entrada na vida adulta, no enlace entre o biográfico e o geopolítico. Persépolis, como dissemos, pode ser compreendida como tentativa de abrir uma outra visibilidade para os iranianos, e, em seu projeto comunicativo, dirige-se estrategicamente a um leitor ocidental por meio de um gênero da cultura de massa, os quadrinhos. No entanto, estabelece uma espécie de exílio no pop, que não apenas proporciona a fronteira cultural própria das diásporas como expõe como frágeis algumas dicotomias entre formas consideradas apropriadas de testemunho e cultura midiática. Para Amy Malek (2006: 379, tradução nossa), essa liminaridade permite à desenhista "fundir gêneros ocidentais memorialísticos e quadrinhos com a história e a cultura iranianas e suas próprias sensibilidades conturbadas para criar um 'terceiro espaço' a partir do qual falar e narrar seu conto híbrido"7. 
No que se refere à fusão entre memória e quadrinhos, Maus, a obra de Art Spiegelman, abriu o caminho a seu modo. No entanto, como Huyssen (2003) assinala, os quadrinhos de Spiegelman sobre a Shoah são saturados de técnicas modernistas, como reflexividade, fragmentação temporal e autoironia, na condição de estilemas cultos. Na demarcação de sua consciência linguageira, Maus reitera também o dilema do "indizível" e a crise da representação, como se sua mímesis devesse ser inibida, não só pela estratégia de desenhar as personagens como animais antropomorfizados, mas por digressões reflexivas. No primeiro capítulo de Maus II, na passagem em que Art e sua esposa Françoise se dirigem à casa de Vladek - pai de Art cujas memórias são narradas - o autor ali representado vacila em face do testemunho de uma realidade que ele considera complexa demais para ser visualizada: "É muito esquisito tentar reconstruir uma realidade pior do que os meus sonhos mais pavorosos. E ainda por cima em quadrinhos! Acho que estou dando um passo maior do que as pernas. Talvez seja melhor deixar para lá." (SPIELGELMAN, 2009: 176). No segundo capítulo desse mesmo volume, a crise retorna e Art, com máscara de rato, diz que:

Em setembro de 86 , depois de oito anos de trabalho, a primeira parte de Maus foi publicada. Um sucesso de crítica e vendas. No mínimo quinze edições estrangeiras estão para sair. Recebi quatro convites para transformar o livro em filme ou especial para tv. (Não quero). (SPIEGELMAN, 2009: 201)

No quadro final da página, Art debruça-se sobre uma prancheta, tendo a seus pés uma montanha de cadáveres de ratos nus sobrevoados por moscas. Fora de quadro, alguém diz: “Ok, sr. Spiegelman... Podemos rodar!...” (SPIEGELMAN, 2009: 201). Para Huyssen, essa obsessão da indústria cultural com o holocausto quase consegue abortar a empreitada de Spiegelman, em momento de crise que dá a ver o paradigma da "recusa em narrar" ou "do silêncio traumático" das próprias testemunhas.

À diferença de Spiegelman, Satrapi parece não se importar com a intermidialidade ou com a circulação de seus traços pelo mundo pop, mesmo que - sem pretender, aqui, estabelecer qualquer comparação entre experiências - suas memórias, notadamente as que compõem Persépolis, também abordem eventos traumáticos relacionados a execuções, estupros, guerras e ao exílio. Como dissemos, tanto Persépolis como a terceira obra de Satrapi, Frango com ameixas, foram adaptadas para o cinema. O primeiro filme foi indicado ao Oscar de 2008 na categoria de melhor animação; o segundo possui elenco estelar, ainda que à europeia (Mathieu Amalric, Maria de Medeiros, Isabela Rosselini, entre outros). Os desenhos de Satrapi ilustraram a capa e o encarte do disco Préliminaires, de Iggy Pop, um dos dubladores do filme Persépolis para o inglês, e a autora participou, na última década, de inúmeros projetos, que incluem um mural em Barcelona e galerias de arte na Europa. Como assinala Malek (2006), Persépolis tornou-se um best seller (em 2004, já havia vendido mais de 500 mil exemplares), sendo usado em escolas dos Estados Unidos como material paradidático em aulas sobre gênero e ciência política. "Além disso, os quadrinhos e ilustrações de Satrapi foram publicados em periódicos através do mundo, incluindo Libération, El Pais, Internazionale, Flair,

${ }^{8}$ No original: "Additionally, Satrapi's comic and illustrations have been featured in publications across the globe, including Libération, El Pais, Internazionale, Flair, The New York Times, and The New Yorker." The New York Times e The New Yorker" (MALEK, 2006: 369, tradução nossa).

\section{Caminhos de volta}

O cosmopolitismo dessas narrativas é bastante afinado ao entretenimento ocidental, mas sua forma torna-se também subversiva na sociedade iraniana pós-revolucionária, que se opõe aos produtos da indústria cultural ocidental. Nesse sentido, a ambiguidade das formas de expressão do pop tanto pode indicar aderência ao consumo, aos valores hegemônicos do capitalismo na cultura, como, deslocando-se a cultura e o contexto, um sentido mais explícito de inadequação. Huyssen (1986) descreve a experiência da apropriação subversiva do pop, em meados da década de 1960, pela juventude alemã da Republica Federativa. 
${ }^{9}$ No original: "In short, pop became the synonym for the new life of the younger generation, a life style which rebelled against authority and sought liberation from the norms of existing society".
“Em resumo, o pop se tornou sinônimo para um novo estilo de vida da geração mais jovem, um estilo de vida que se rebelou contra a autoridade e procurou a libertação das normas da sociedade existente" (HUYSSEN, 1986: 141, tradução nossa) $)^{9}$. A noção do pop, naquele contexto, não se restringia à arte de Hamilton, Warhol e Lichtenstein, entre outros, mas se estendia sobre manifestações, em geral, consideradas underground e contra o sistema (o rock, a cena das drogas e do amor livre, arte do pôster etc.).

Em Persépolis, no capítulo "Kim Wilde", a personagem caminha pela avenida Gandhi para comprar fitas cassetes de músicos e cantores ocidentais, oferecidas comicamente às escondidas e aos sussurros, como se fosse uma situação de tráfico de drogas: "Istivi Vonder, Abba, Bee Jees, Yazzo, Julio Iglesias, Pink Floyd..." (SATRAPI, 2007a: s. p.). Pega com um broche de Michael Jackson, por duas "guardiãs da revolução", a menina busca se safar dizendo tratar-se não do cantor, considerado um "símbolo da decadência", mas de Malcom X, "o líder dos negros muçulmanos americanos". Nesse mesmo capítulo, os pais de Satrapi viajam a Istambul e, a pedido da filha, "traficam" para Teerã pôsters dos britânicos da banda de heavy metal Iron Maiden e da cantora pop Kim Wilde.

Por outro lado, esses quadrinhos são bastante críticos em relação a costumes ocidentais e às intervenções norte-americanas e inglesas no Oriente. Em Frango com ameixas, a personagem Mozaffar, filho do protagonista Nasser Ali Khan, migra, após a revolução, para os Estados Unidos, onde realiza o "sonho americano" ao preço da idiotia (das frases feitas, do consumo, da ideologia do vencedor). No filme, essa mesma história é narrada com a mise-en-scène de um sitcom (como Oliver Stone fizera com vida de Mallory Knox, personagem de Juliette Lewis em Assassinos por natureza), o que nos coloca a questão se a estratégia é, afinal, a de se combater um estereótipo por meio de outro. Isto é, na medida em que Satrapi devolve a determinado leitor-espectador ocidental a imagem dele estereotipada suas narrativas acabariam por colocar em relevo o caráter tacanho das representações cristalizadas em geral.

O humor nessas narrativas assume, por vezes, uma forma rebaixada, em que podemos ver um gesto político. Nos episódios de Bordados, sua segunda obra traduzida no Brasil, mulheres iranianas reúnem-se após o almoço, enquanto os homens fazem a sesta, para conversar e tomar chá, ao redor do samovar, tradicional bule oriental. Nos quadrinhos, os diálogos tratam abertamente da sexualidade das iranianas e deles saem histórias como a da esposa que nunca tocou ou mesmo viu o "órgão masculino" do marido e a de Nahid, que, tendo perdido a virgindade com um outro antes do casamento, leva para noite de núpcias uma gilete para se cortar e fingir o sangramento, mas acaba por cortar o testículo do marido. Em Bordados, porém, passa-se com vigor do escárnio à ironia reflexiva, nesse tônus admirável que possuem os quadrinhos de Satrapi. Ao fundo do anedótico, como a borra do chá, permanecem desconfortáveis imposições do regime e da cultura, que as iranianas ali reunidas, em sua diversidade, tentam recusar: os casamentos arranjados e consumados ainda na adolescência; a exigência da virgindade, que faz com as mulheres recorram à operação de reconstituição do hímen (o bordado, como um dos sentidos propostos ao título da obra); a submissão ao homem.

Na boa leitura que Amy Malek (2006) fez de Persépolis, ironia e humor são modos de Satrapi lidar com a dor e tornam-se elementos-chave para que os leitores permaneçam engajados e atravessem as partes difíceis, que incluem cenas de tortura, guerra e tentativa de suicídio. Sobre os relatos de "pós-memória", Hirsch (2008) interpreta algo semelhante, ao indicar que as imagens que medeiam esses relatos são como uma tela que absorvem o choque e filtram e dissipam o horror do trauma, embora, paradoxalmente, elas reforcem uma conexão com o passado.

Ainda como estratégias cativantes de Persépolis, Malek (2006) cita a narrativa no ponto de vista da criança, nas primeiras partes do livro; o modo como os cenários são 
construídos, em desenho preto e branco simples, próximos à cotidianidade de um leitor ocidental e cosmopolita, privilegiando elementos como a tevê, a sala de cinema, o sofá e o supermercado, ao invés, por exemplo, de tapetes e travesseiros iranianos ou um bazar; a forma despretensiosa e autorreflexiva da narrativa, que inclusive expõe os desvios da protagonista, humanizando-a. Em uma cena, a personagem, já adulta, acusa um homem iraniano de assédio para desviar a atenção de uma patrulha, que possivelmente iria repreendê-la pelo uso de maquiagem. $O$ homem é preso e Satrapi, ao contar, em tom de chiste, o caso à sua avó, é severamente repreendida: "E você acha isso engraçado? Esqueceu quem foi seu avô? Passou um terço da vida na cadeia por ter defendido inocentes (...) A integridade!!! Essa palavra te diz alguma coisa?" (SATRAPI, 2007a: s. p.). Embora afirme, até mesmo para a própria proteção, a ficcionalidade da autobiografia, Satrapi (2007) reconhece como suas as muitas incorreções ali narradas e que sua vida, emprestada à personagem, é, como nos quadrinhos, distante da perfeição, que considera "um princípio do fascismo".

O pensamento e cenários que identificamos como ocidentais não apagam, contudo, o movimento que evoca aquela conhecida narradora do Oriente que, buscando vencer a morte, retira uma história de dentro da outra. O gesto, bem mais preciso em Frango com ameixas, inclui, nessa mesma fiç̧ão, a história de um homenzinho, Ashur, que, encontrando-se com o anjo Azhael em Jerusalém, pede, assustado, a Salomão para ser transportado, pelo vento, para o Taj Mahal, onde trágica e ironicamente irá se encontrar novamente com a Morte, que, antes de levá-lo, explica sua surpresa: "Ontem, o senhor estava em Jerusalém, e eu tinha que lhe dar o golpe de misericórdia hoje, na Índia. Eu me perguntava como o senhor faria para chegar aqui em tão pouco tempo" (SATRAPI, 2008: s.p.). Se no plano das personagens essa é uma batalha perdida, no da autora o empenho persiste no exílio, em seu projeto memorialístico, também de corte nostálgico. O caráter fronteiriço da diáspora é constantemente evocado, nas ficções, pelo paladar e pelo olfato. Seja na receita de família do frango com ameixas, no chá agregador de Bordados ou na flor de jasmim que a avó, em Persépolis, colocava diariamente entre os seios para permanecer perfumada, cada narrativa abre, sempre, um caminho de volta para o Oriente.

\section{Algumas considerações finais}

A dialética do localismo e do cosmopolitismo nas narrativas de Satrapi apenas superficialmente pode ser compreendida, como na separação didática entre enunciado e enunciação, pela relação entre um conteúdo e uma forma de expressão. Nesse caso, que, afirmamos, é o de uma simplificação, o elemento local, isto é, a história cultural do Irã é colocada em enredo, como assinala Malek (2006), por um gênero da cultura midiática ocidental, a graphic novel. A perspectiva de Satrapi parece-nos, no entanto, mais complexa, pois tanto na matéria narrada como no campo da expressão há graus dessa dialética.

O que há de "cor local" nessas narrativas, para usarmos um termo caro à programática romântica, é também uma narrativa que busca escapar aos estereótipos que os ocidentais fazem dos iranianos e de sua cultura. A perspectiva da narradora em Persépolis é o de uma mulher, criada em uma família de valores progressistas e com parte de sua educação à europeia. Nessas obras, falar por meio da perspectiva de uma iraniana não é, absolutamente, como vimos, fazer a defesa da revolução islâmica (não é exatamente, nesse ponto, que o romance gráfico faz frente a narrativas midiáticas dominantes), mas, antes, colocar em relevo a autonomia de pensamento, as formas de transgressão e consciência política que subsistem em determinado segmento daquela sociedade - que não é unívoca -, privilegiando-se as personagens femininas. A avó de Satrapi é uma dessas personagens fortes que migram de uma narrativa a outra, com determinado protagonismo. Nesse ponto, o localismo, como condição iraniana, que se quer expor é aquele que também representa um afinamento com o cosmopolitismo. 
O principal gesto político de Frango com ameixa, por exemplo, talvez seja o de projetar imagens de uma Teerã que é também a dos cafés, do conserto de música, do jogo e de outros vícios, da vestimenta ocidental que convive naturalmente com trajes considerados típicos. Na adaptação cinematográfica, o tar, instrumento persa de cordas que o protagonista domina nos quadrinhos, é trocado pelo violino, o que familiariza e compartilha ainda mais a sensibilidade musical iraniana com os contextos cosmopolitas das audiências.

O mesmo pode-se dizer da enunciação, ela própria construída nessa dialética. 0 modo como os narradores - épicos, como instância sensivelmente mediadora contam suas histórias é o da narrativa-moldura, o da colocação em abismo, que sugere o movimento contínuo de As mil e uma noites. Inserir-se na cultura midiática é, para Satrapi, imprescindível, hoje, tanto para narração da memória como para desconstrução e reconstrução de identidades. Sua obra, de um modo geral, confirma que, para sua geração, as imagens também são dignas do testemunho e a forma pop-de um romance gráfico, de uma animação ou de outras não ficções - pode vir a ser a expressão potente de um trauma em um contexto mundializado.

\section{Referências Bibliográficas}

CANDIDO, Antonio. Literatura e cultura: de 1900 a 1945. In: CANDIDO, Antonio. Literatura e sociedade. 8a. ed. São Paulo: T. A. Queiroz, 2000. p. 109-138.

HIRSCH, Marianne. The generation of postmemory. In: Poetics today. Porter Institute for poetics and semiotics, v. 29, n. 1. Spring, 2008. p. 103-128.

HUYSSEN, Andreas. After the great divide. Bloomington, Indianapolis: Indiana University Press, 1986.

HUYSSEN, Andreas. Of mice and mimesis: reading Spiegelman with Adorno. In: HUYSSEN, Andreas. Present pasts: urban palimpsests and the politics of memory. Stanford, California: Stanford University Press, 2003. p. 122-137.

MACHADO, Arlindo. O quarto iconoclasmo e outros ensaios hereges. Rio de Janeiro: Rios Ambiciosos, 2001.

MALEK, Amy. Memoir as Iranian Exile Cultural Production: a case study of Marjane Satrapi's Persepolis series. In: Iranian studies, v. 39, n. 3, September, 2006. p. 353-380.

RANCIÈRE, Jacques. A imagem intolerável. RANCIÈRE, Jacques. O espectador emancipado. Trad. José Mirando Justo. Lisboa: Orfeu Negro, 2010. p. 123-153.

SATRAPI, Marjane. Interview to Robert L. Root. Fourth genre: explorations in nonfiction. Michigan State University Press, v. 9, 2007. p. 147-157.

SATRAPI, Marjane. Persépolis. São Paulo: Companhia das Letras, 2007a.

SATRAPI, Marjane. Frango com ameixas. São Paulo: Companhia das Letras, 2008.

SATRAPI, Marjane. Bordados. São Paulo: Companhia das Letras, 2010.

SATRAPI, Marjane. "On writing Persepolis, as told to Pantheon staff”. Disponível em: http://engres.ied.edu.hk/lang_arts/onlineRead/graphicNovel/PersepolisLesson_ RandomHouse.pdf. Acesso em: 03 de outubro de 2013.

SELIGMANN-SILVA, Marcio. O local da diferença. - ensaios sobre memória, arte, literatura e tradução. São Paulo: Ed. 34, 2005. 
SPIEGELMAN, Art. Maus. São Paulo: Companhia das Letras, 2009.

WEBER-FÈVE, Stacey. Framing the "minor" in Marjane Satrapi and Vincent Paronnaud's Persepolis. In: Contemporary French and Francophone Studies. v. 15, n. 3, June 2011, p. 321-328. 